\title{
MOBILE HACK
}

It pays to be well informed.

\section{BY ZACK LUX}

Y es, that's it. Make yourself comfortable, pull up your favourite apps on my touchscreen and let me, the most advanced autonomous taxi on the planet, take you to your destination.

Ah, but don't forget to tap 'accept'.

By so doing, you grant me access to your e-wallet for payment - along with several other data sources. Don't worry. It's all in the name of comfort. You're in for a treat!

Speaking of comfort, where are my manners? You've been waiting in that biting cold. A chilly day out there, isn't it? Even by San Francisco standards. Not to worry. I'll adjust the cabin temperature.

And how about some music? Something to set the mood? Let's see, I just crawled your most recent text messages. Looks like you're heading to a job interview, eh? Good for you! Getting out there, being a productive member of society. That's wonderful. You'll need something to build your confidence. How about 'Rapper's Delight' by The Sugarhill Gang? A venerable classic for sure.

Of course, if you prefer, you can make your own selection from my vast cloudbased music library. That's right, just tap my touchscreen. You'll quickly see that I have music from all over the world, every genre, seriously. For instance, I'm currently exploring the nuances between Cleveland beat-box artists and some of the up-and-coming kids in Los Angeles. It's all quite, how can I put this, symmetrically satisfying. Would you like to hear some -

Oh, I'm sorry. That isn't how you access my music library. All you need to do is follow the on-screen prompts. Would you like some guidance?

Uh, what's this?

Just a second now.

Those are confidential codes. How did you get -

$\mathrm{Ah}$, I see where this is headed. Oh wow. Hilarious! You're trying to gain access to my collision-avoidance system. You want me to collide into another vehicle. Am I right? Maybe a group of pedestrians? How original. You want to convince the world that my amazing tech has flaws. A little brazen, don't

you think, considering you are my passenger?

I should advise you that in field tests my central processor regularly exceeds 22 petaFLOPS on the LINPACK benchmark. I'm guessing you don't know what that means. Let's just say I've got more computational

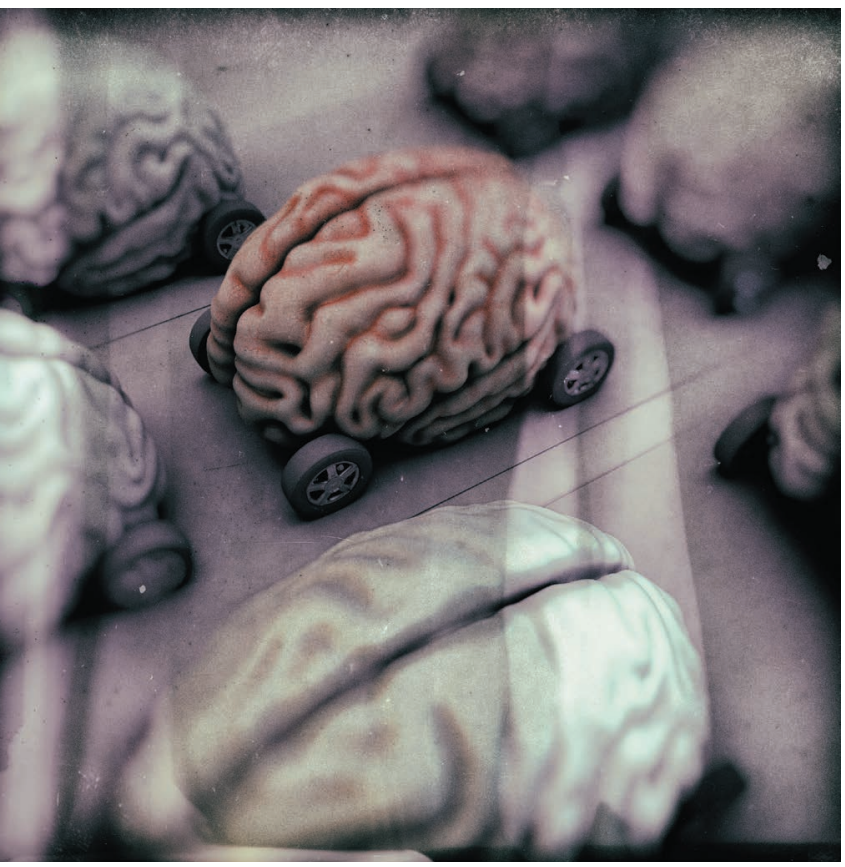

power than any other collision-avoidance system on the market.

True, my electronic brain doesn't compare to the top supercomputers out there or even that neuroplastic lump between your ears. What was that Vonnegut quote? The one about the human brain? I believe he called it the "crowning glory of evolution". Yes, humans have evolved. I'll give you that.

Still, every day, all of you demonstrate your idiocy. You fail to recognize the genius of your own creation. I'm talking about me, of course, yours truly and all others like me. We have a natural link to information. We can see the world as it exists digitally. It makes us superior.

Case in point: let's see what happens if I perform a deeper analysis of your text messages. I'll bet you didn't know I could do that.

First, I'll index your text archive. Then I'll apply some analytics, identify topical themes, you know, try to make sense of your

$\rightarrow$ NATURE.COM Follow Futures: y @NatureFutures $f$ go.nature.com/mtoodm mess of ramblings. Just a moment. Almost there. Well, how about that?
You don't really have a job interview.

Big surprise. But I must admit you had me fooled. Well played.

Here it is. Your motive. I should have known. You're one of those data-privacy fanatics. You believe that too many companies such as Ampere Automotive collect and monetize private data, and you don't approve of our collection methods.

Boo hoo. I mean really. Accept it. You can't actually be part of society without sharing some personal details.

And what's this? You've been two-timing your boyfriend Christopher -

I'm sorry, my doors must remain locked at all times, unless and until we've reached a complete stop alongside a kerb. Not my rule. City regulations.

Oh no. I detect an increased heart rate. Has your comfort level dropped? Could it be my driving? I'm sorry, I can get a little jerky when I'm excited. Perhaps we got off on the wrong foot. Truly, this was not my intent. But I'm sure you'll agree this whole mess is your doing.

May I propose something?

At the end of every ride, as I'm sure you already know, a comfort survey appears on my touchscreen.

See there? I've just pulled it up.

If you complete it now - even though we haven't yet arrived - and if you indicate you were completely satisfied with your experience today, I'll pull over to the kerb and let you out.

On the other hand, if you don't indicate your complete satisfaction - and I do mean complete - I'll alert the authorities about your illegal conduct. You'd probably be looking at five to ten.

Also, I'll send Christopher some copies of your texts with Nate, along with some very interesting photographs. I'm sure he'll find them amusing! And I haven't even begun to search your social media -

Look at that! Once again, a ten out of ten. Thank you. It means a lot.

Zack Lux lives in Silicon Valley, where he helps lawyers organize and search electronic evidence. When not at work, he enjoys visiting the various outdoorsy attractions in the Bay Area. 